\title{
A Computational Study of a Prebiotic Synthesis of the Steroid Progesterone (A and B Rings)
}

\author{
NIGEL AYLWARD \\ School of Chemistry and Molecular Biosciences \\ University of Queensland \\ Brisbane, Queensland \\ AUSTRALIA \\ uqnaylwa@uq.edu.au
}

\begin{abstract}
The magnesium ion metalloporphyrin complex is shown to bind the ligands propyne (p) and ethyne (e) on the metal or nitrogen pyrrole sites as a two site catalyst in their copolymerization. The order of addition of the monomers is (pepeeepee). The steroid ring D (pep) is formed first from the propyne adduct bound to the metal site and the but-diene adduct bound to the $\mathrm{N}$-site. The optimal orientation of these adducts determines the $\beta$-orientation of the 17 -substituent. Further reaction with hydroxyl radicals allows this to be a $17 \beta$-acetyl substituent. Further addition of three ethyne monomers forms a N-tri-ene cyclopentene derivative able to cyclise to form the steroid ring $C$ (pee) with a trans conformation and a $13-\beta$ methyl substituent.. Further binding of propyne on the metal site together with the $\mathrm{N}$-indenyl bound adduct enables the B-ring (eep) to form with a trans orientation and a 10- $\beta$-methyl substituent. Further addition of two ethyne monomers to the Mg.porphin.N-phenanthrenyl bound adduct allows cyclisation to form the A-ring (pee). The polymerization is curtailed by reaction with hydroxyl radical to form the 3-keto substituent. The cleavage of the Mg.porphin catalyst produces the double bond of pregnane-4,5-diene-3,20-dione.

The reactions have been shown to be feasible from the overall enthalpy changes in the ZKE approximation at the HF and MP2 /6-31G* level, and with acceptable activation energies.
\end{abstract}

Key-Words: - Prebiotic photochemical synthesis, progesterone (A \& B rings), propyne, ethyne, Mg.porphin.

Received: June 14, 2019. Revised: January 6, 2020. Accepted: January 20, 2020. Published: February 5, 2020.

\section{Introduction}

Progesterone, pregn-4-ene-3,20-dione [1], a progestational hormone [2] which binds to a specific receptor [3] is a derivative of the saturated tetracyclic hydrocarbon, perhydrocyclopentane phenanthrene [4]. This has six centres of asymmetry [4] arising from the fusion of the four rings where the numbering and designation are standard [1]. This steroid is closely related to the terpenes [5] constructed of multiples of the fivecarbon hydrocarbon isoprene (2-methyl-1,3butadiene). The biosynthesis of progesterone is from the steroid cholesterol [4], which in turn is derived from the steroid lanosterol [4] formed from the isoprene units of squalene (a dihydrotriterpene) consisting of consecutive isoprene units [4].

From a prebiotic perspective [6] it is desirable if the reactant molecules formed spontaneously from a supposed prebiotic atmosphere to be inevitably present. It has often been held that the atmosphere of the Earth was originally mildly reducing [4,7] implying the presence of concentrations of carbon monoxide, ammonia, water and hydrogen. It is also supposed that ethyne (e) and propyne (p) were present as found in interstellar space $[8,9]$ and present on Titan, a moon of Saturn. It has also been demonstrated that porphin may act as a cat alyst for the formation of sugars [10] and terpenes [11].

This paper proposes a m odel for the catalytic photochemically activated copolymerization of these gases to form progesterone where the order of polymerization is pepeeepee on the catalyst magnesium porphin, and involves some hydroxylation and hydrogenation.

The reactions described have been deduced as kinetically and thermodynamically viable, but photochemical excitation is required. 


\section{Problem Formulation}

This proposed computational study of a plausible synthesis of the steroid progesterone involves the calculation of the enthalpy changes for reaction intermediates in the ZKE approximation and the calculation of activation energies at the HF level. These activation energies may all be accessible as the catalyst may absorb appreciable photochemical activation $(0.21 \mathrm{~h})$. The computations tabulated in this paper used the GAUSSIAN03 [12] commercial package. The standard calculations at the HF and MP2 levels including zero-point energy corrections at the Hartree Fock level, [13], together with scaling [14], using the same basis set, 6-31G*. are as previously published [6]. Enthalpy changes at the MP2 level not including scaled zero point energies are designated as $\Delta \mathrm{H}_{(\mathrm{MP2})}$. The charge transfer complexes are less stable when calculated at the Hartree Fock level [13], and activation energies calculated at the HF level without scaling are less accurate.

If the combined energy of the products is less than the combined energy of the reactants it may show that the reaction is also likely to be spontaneous at higher temperatures. This paper uses the atomic unit of energy, the hartree [12].

$1 \mathrm{~h}=627.5095 \mathrm{kcal}^{\mathrm{mol}} \mathrm{l}^{-1} .1 \mathrm{~h}=4.3597482 \times 10^{-18} \mathrm{~J}$ Charges are in units of the electronic charge.

\section{Problem Solution}

\subsection{Total Energies (hartrees)}

The steroid is described as being formed as a copolymerzation of the gases ethyne and propyne on the two site catalyst Mg.porphin. References prefaced by steroid refer to the standard steroid numbering as shown, Fig.1 [1].

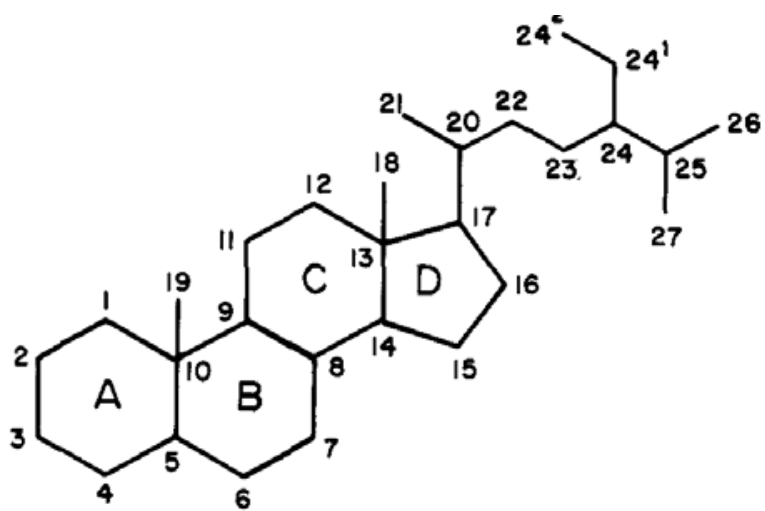

Fig.1. Standard steroid substituent numbering. [1]
3.2 The formation of Mg.1,ethynyl porphin. 4-( 5-acetyl-2-dehydro-1-methyl cyclopent3-en-1yl)-but-1,3-dien-N1-yl

Previously [15] it has been shown how the C-ring may form from the cyclisation of the Mg.1,porphin.4-( 5-acetyl-2-dehydro-1-methyl cyclopent-3-en-1yl) but-1,3-dien-N1-yl, designated here as, Mg.porphin. $\mathrm{C}_{12} \mathrm{H}_{14} \mathrm{O}$. However, a lower activation energy is apparent if a further ethyne is added before the C-ring closes with the required rotations as previously calculated [15]. The further addition of ethyne to the cyclopentene entity, pepee, is depicted as,

ethyne + Mg.1,porphin. 4-( 5-acetyl-2-dehydro-1methyl cyclopent-3-en-1yl)-but-1,3-dien-N1-yl

(1)

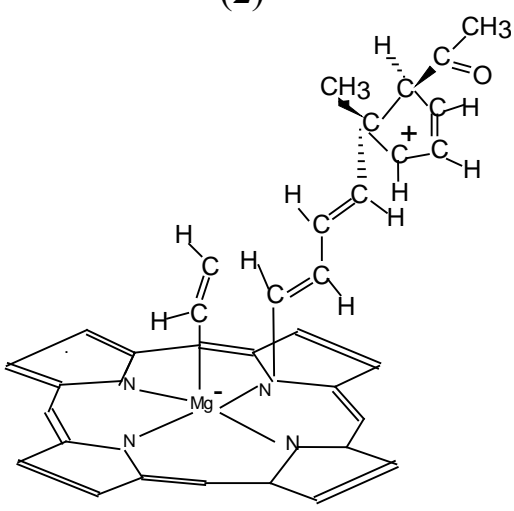

Mg.1,ethynyl porphin.4-(5-acetyl-2-dehydro-1methyl cyclopent-3-en-1yl)-but-1,3-dien-N1-yl. (3)

$$
\Delta \mathrm{H}=0.08009 \mathrm{~h}
$$

The charges on the adducts were: ethyne, 0.09 , cyclopentene entity, -0.54 , respectively.

The energies of the stable complexes involved in the formation of the $\mathrm{A}$ and $\mathrm{B}$ rings are given in Table.1.

Table 1

MP2 /6-31G* total energies and zero point energies (hartrees) for the respective equilibrium geometries

$\begin{array}{lll}\text { Molecule } & \begin{array}{l}\text { MP2 } \\ \text { hartree }\end{array} & \text { ZPE (HF) } \\ \text { hartree }\end{array}$

ethyne (1) $\quad 77.06679 \quad 0.02945$

Mg.1,porphin. 4-(5-acetyl-2-dehydro-1-methyl cyclopent-3-en-1yl)-but-1,3-dien-N1-yl. (Mg.porphin. $\mathrm{C}_{12} \mathrm{H}_{14} \mathrm{O}$ ) (2) -1724.13701 0.53222 Mg.1,ethynyl porphin.4-(5-acetyl-2-dehydro-1methyl cyclopent-3-en-1yl)-but-1,3-dien-N1-yl (3)

Mg.porphin (4) $\quad-1185.12250 \quad 0.29262$ 
progesterone (5)

$-965.531670 .50789$

Mg.1,6-(5-acetyl-2-dehydro-1-methyl cyclopent-3en-1yl )-hex-1,3,5-trien-1yl.porphin (6) $\begin{array}{lll}-1801.16476 & 0.55873\end{array}$

Mg.1,porphin.6-( 5-acetyl-2-dehydro-1-methyl cyclopent-3-en-1yl)- hex-1,3,5-trien-N1-yl.(7) $-1801.098730 .56821$

Mg.1,porphin.2-(9H-1-acetyl-8-methyl-inden-4yl)-ethen-N1-yl.(8) $-1801.155730 .57536$ Mg.1,propynyl.porphin.2-(9H-1-acetyl-8-methylinden-4-yl)-ethen-N1-yl. (9)

$$
-1917.34973 \quad 0.63687
$$

Mg.1,2-(9H-1-acetyl-8-methyl-4-ethen-N2-yl inden-5-yl)-propen-1-yl.porphin. (10)

$$
-1917.464550 .64613
$$

Mg.1,des-A-6,7,11,12,15,16-hexa-dehydropregnan-5-yl.porphin (11) -1917.65609 0.64337 Mg.1,porphin.des-A-6,7,11,12,15,16-hexadehydro-pregnan-N5-yl. (12)

$$
-1917.520780 .64705
$$

Mg.1,ethynyl.porphin.des-A-6,7,11,12,15,16hexa-dehydro-pregnan-N5-yl.(13)

$$
-1994.667710 .67609
$$

Mg.1,2-(10-des-A-6,7,11,12,15,16-hexa-dehydropregnan-N5-yl)- ethen-1-yl.porphin (14) $-1994.634530 .68483$

Mg.1, porphin.2-(des-A-6,7,11,12,15,16-hexadehydro-pregnan-10-yl)-ethen-N1-yl. (15) (15) $-1994.572000 .68092$

Mg.1,ethynyl.porphin. 2-(des-A-6,7,11,12,15,16hexa-dehydro-pregnan-10-yl)-ethen-N1-yl (16) $-2071.647820 .71195$

Mg.1,4-(des-A-6,7,11,12,15,16-hexa-dehydropregnan-10-yl)-but-1,3-dien-1-yl.porphin (17) $-2071.81395 \quad 0.71567$

Mg.1,1,2, 6,7,11,12,15,16-octa-dehydro-pregnan4-yl.porphin. (18) $\quad-2071.948600 .71831$

Mg.1,1,2, 6,7,11,12,15,16-octa-dehydro-3hydroxy-pregnan-4-yl.porphin: (19) $-2147.453860 .73635$

1,2,6,7,11,12,15,16-octa-dehydro-3-hydroxypregnane. (20) $-961.888080 .43149$ $1,2,6,7,11,12,15,16$-octa-dehydro-pregnane (21) $-960.737410 .40576$ pregn-4-ene-3,20-dione ( progesterone_(22)

\begin{tabular}{lcc} 
& -965.53167 & 0.50789 \\
propyne (5) & 116.24181 & 0.06010 \\
$\mathrm{H}_{2} \mathrm{O}$ & -76.19685 & 0.02298 \\
$\mathrm{OH}^{\cdot}$ & -75.52257 & 0.00911 \\
$\mathrm{H}_{2}$ & -1.14414 & 0.01059 \\
\hline
\end{tabular}

\subsection{The overall stoichiometry for the formation of the steroid: progesterone (A \& $B$ rings)}

Although Mg.porphin is here taken as the catalyst for the reaction, the overall stoichiometry to form the $\mathrm{A}$ and $\mathrm{B}$ rings of progesterone is as follows,

Mg.porphin. $\mathrm{C}_{12} \mathrm{H}_{14} \mathrm{O}(2)+3 \mathrm{H}-\mathrm{C} \equiv \mathrm{C}-\mathrm{H}+\mathrm{CH}_{3}-\mathrm{C}$ $\equiv \mathrm{C}-\mathrm{H}+\mathrm{H}_{2} \mathrm{O}+2 \mathrm{H}_{2} \rightarrow$ Mg.porphin $+\mathrm{C}_{21} \mathrm{H}_{30} \mathrm{O}_{2}$

progesterone (5)

$$
\Delta \mathrm{H}=-0.52248 \mathrm{~h}
$$

The enthalpy change is negative indicating that this may be the energetically favourable route to the initial formation of the steroid. The intermediates by which these stoichiometric reactions may have occurred are as follows

3.4 The formation of Mg.1, 6-( 5-acetyl-2dehydro-1-methyl cyclopent-3-en-1yl )-hex1,3,5-trien-1yl. porphin.

The bonding of the Mg.1, ethynyl porphin.4-(5acetyl-2-dehydro-1-methyl cyclopent-3-en-1yl)but-1,3-dien-1yl adducts is represented as,

Mg.1,ethynyl porphin.4-(5-acetyl-2-dehydro-1methyl cyclopent-3-en-1yl)-but-1,3-dien-1yl $\rightarrow$

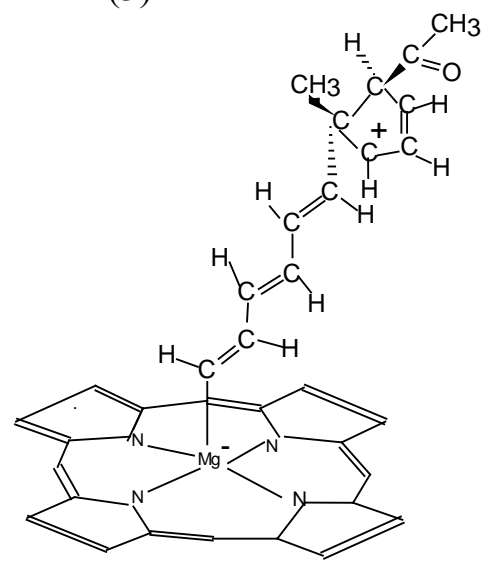

Mg.1,6-(5-acetyl-2-dehydro-1-methyl cyclopent-3en-1yl )-hex-1,3,5-trien-1-yl. porphin. (6) [3]

$$
\Delta \mathrm{H}=-0.04367 \mathrm{~h}
$$

The form of the potential energy surface is given in Fig. 2 


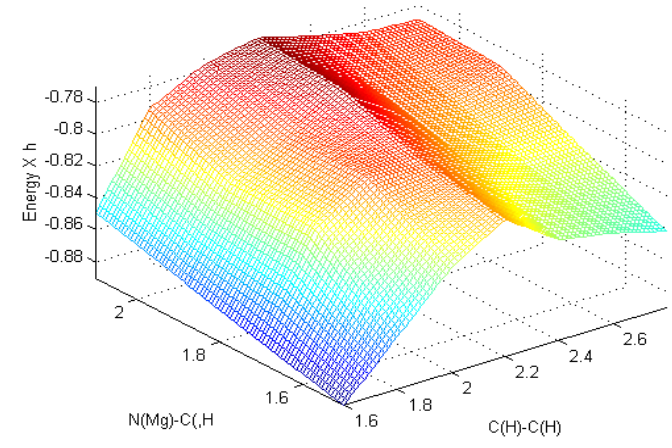

Fig.2. The reactant is near $(3.0,1.5)$, the product at $(1.6,1.5)$. The saddle point at $(2.2,1.5)$. The energy is $-1795+\mathrm{Xh}$.

The activation energy to form the product was, $0.074 \mathrm{~h}$, whilst for the reverse reaction, $0.119 \mathrm{~h}$. A further activation energy of $0.041 \mathrm{~h}$ is required to sever the C-N bond. The charge on the adduct was 0.13 .

3.5 The formation of Mg.1, porphin. 6-( 5acetyl-2-dehydro-1-methyl cyclopent-3-en1yl )-hex-1,3,5-trien-1yl.

The promotion to the higher N-bound state of the adduct may be represented as,

Mg.1,6-(5-acetyl-2-dehydro-1-methyl cyclopent-3en-1yl )-hex-1,3,5-trien-1yl. porphin $\rightarrow$

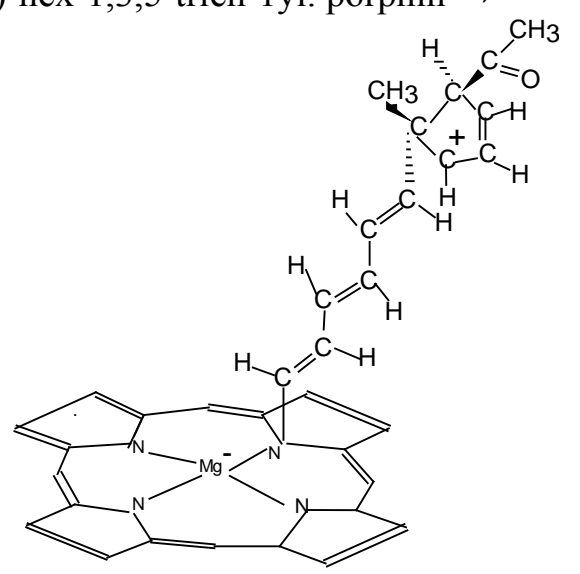

Mg.1,porphin.6-(5-acetyl-2-dehydro-1-methyl cyclopent-3-en-1yl)-hex-1,3,5-trien-N1-yl (7)

$$
\Delta \mathrm{H}=0.07447 \mathrm{~h}
$$

The activation energy was the same as the enthalpy change. The charge on the adduct was 0.23 .

\subsection{The formation of Mg.1,porphin.2-(9H-1- acetyl-8-methyl-inden-4-yl)-ethen-N1-yl.}

The cyclisation involving the rotations previously considered [15] is represented as,

Mg.1,porphin.6-(5-acetyl-2-dehydro-1-methyl cyclopent-3-en-1yl )-hex-1,3,5-trien-N1-yl $\rightarrow$

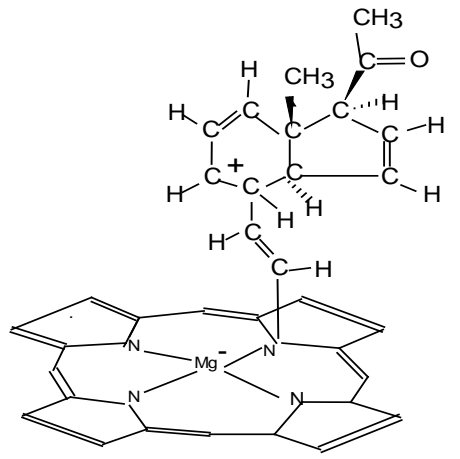

Mg.1,porphin.2-(9H-1-acetyl-8-methyl-inden-4yl)-ethen-N1-yl. (8)

[5]

$$
\Delta \mathrm{H}=-0.05063 \mathrm{~h}
$$

The activation energy to close the $\mathrm{C}$-ring was $0.020 \mathrm{~h}$, and to open the ring, $0.045 \mathrm{~h}$. The charge on the adduct was -0.46 . The closure of this $\mathrm{C}$-ring determines the trans C-D rings and the steroid $\beta$ methyl substituent at $\mathrm{C}-13$.

\subsection{The formation of Mg.1,propynyl.} porphin. 2-(9H-1-acetyl-8-methyl-inden-4yl)-ethen-N1-yl.

The Mg.1,porphin.2-(9H-1-acetyl-8-methyl-inden4-yl)-ethen-N1-yl may add a further propyne molecule on the vacant magnesium site as,

propyne + Mg.1,porphin.2-(9H-1-acetyl-8methyl-inden-4-yl)-ethen-N1-yl. $\rightarrow$

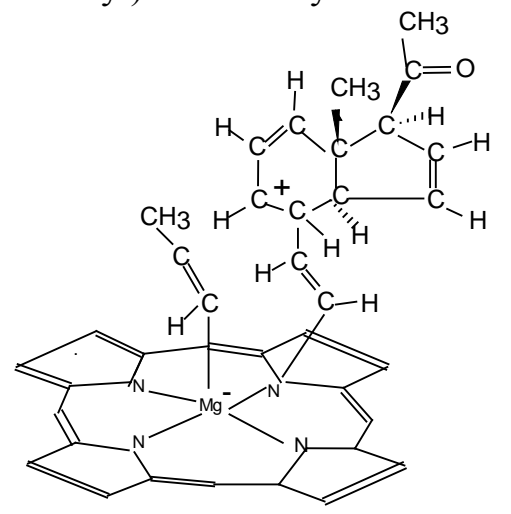

Mg.1,propynyl.porphin.2-(9H-1-acetyl-8-methylinden-4-yl)-ethen-N1-yl. (9)

$$
\Delta \mathrm{H}=0.04906 \mathrm{~h}
$$


The charge on the adducts was: propyne, 0.08 , the indenyl entity, -0.55 .

\subsection{The formation of Mg.1,2-(9H-1-acetyl-8- methyl-4-ethen-N2-yl inden-5-yl)-propen-1- yl.porphin}

The Mg.1,propynyl.porphin. 2-(9H-1-acetyl-8methyl-inden-4-yl)-ethen-N1-yl. may cyclise wth the formation of the trans $\mathrm{B}-\mathrm{C}$ bridge as,

Mg.1,propynyl.porphin.2-(9H-1-acetyl-8-methylinden-4-yl)-ethen-N1-yl. $\rightarrow$

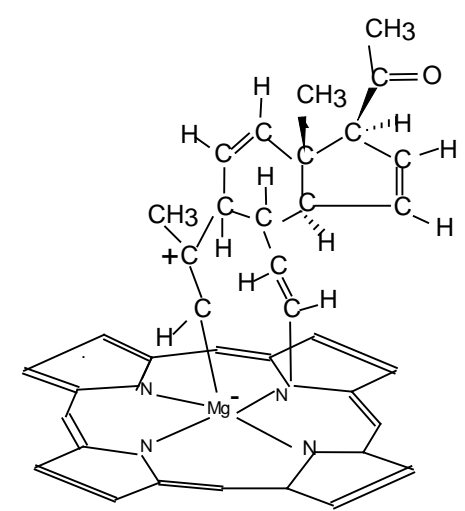

Mg.1,2-(9H-1-acetyl-8-methyl-4-ethen-N2-yl inden-5-yl)-propen-1-yl.porphin. (10)

[7]

$$
\Delta \mathrm{H}=-0.10658 \mathrm{~h}
$$

The activation energy was $0.018 \mathrm{~h}$, and $0.066 \mathrm{~h}$ for the reverse reaction. The charge on the adduct was -0.16 .

\subsection{The formation of Mg.des-A-6,7,11,12,15} ,16-hexa-dehydro-pregnane.porphin

The Mg.1,2-(9H-1-acetyl-8-methyl-4-ethen-N2-yl inden-5-yl)-propen-1-yl.porphin may cyclise as,

Mg.1,2-(9H-1-acetyl-8-methyl-4-ethen-N2-yl inden-5-yl)-propen-1-yl.porphin $\rightarrow$

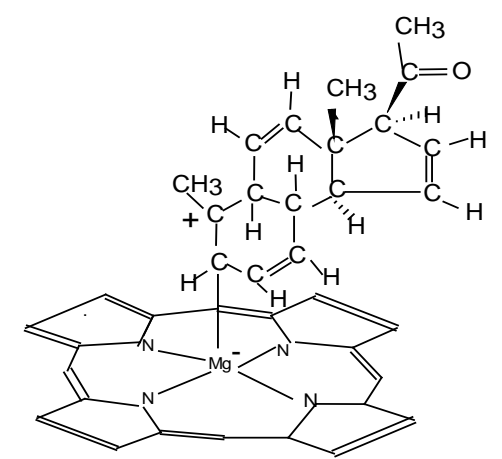

Mg.1,des-A-6,7,11,12,15,16-hexa-dehydropregnan-5-yl.porphin. (11)

$$
\Delta \mathrm{H}=-0.19400 \mathrm{~h}
$$

No activation energy could be recorded during the scan for this bonding. The charge on the adduct was 0.05 .

\subsection{The formation of Mg.porphin.des-A- 6,7,11,12,15,16-hexa-dehydro-pregnane.}

The Mg.1,des-A-6,7,11,12,15,16-hexa-dehydropregnan-5-yl.porphin may be excited to a higher energy state as,

Mg.1,porphin.des-A-6,7,11,12,15,16-hexadehydro-pregnan-5-yl $\rightarrow$

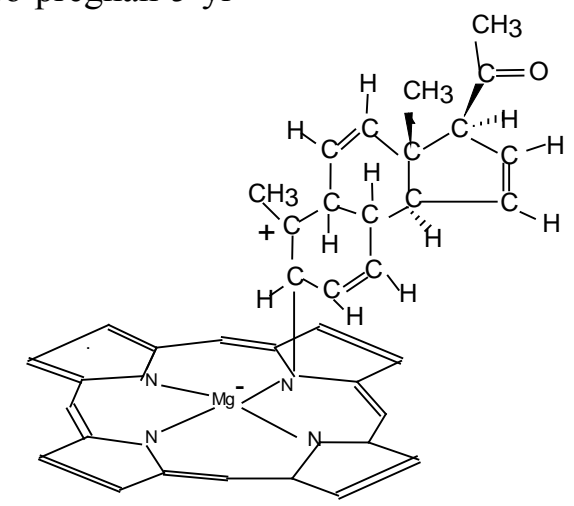

Mg.1,porphin.des-A-6,7,11,12,15,16-hexadehydro-pregnan-N5-yl. (12)

$$
\Delta \mathrm{H}=0.13859 \mathrm{~h}
$$

The activation energy was the same as the enthalpy change. The charge on the adduct was 0.16 .

\subsection{The formation of Mg.1,ethynyl. porphin.des-A-6,7,11,12,15,16-hexa- dehydro-pregnan-N5-yl.}

The Mg.1,porphin.des-A-6,7,11,12,15,16-hexadehydro-pregnan-5-yl may add a further ethyne adduct as,

ethyne + Mg.1,porphin.des-A-6,7,11,12,15,16hexa-dehydro-pregnan-5-yl $\rightarrow$

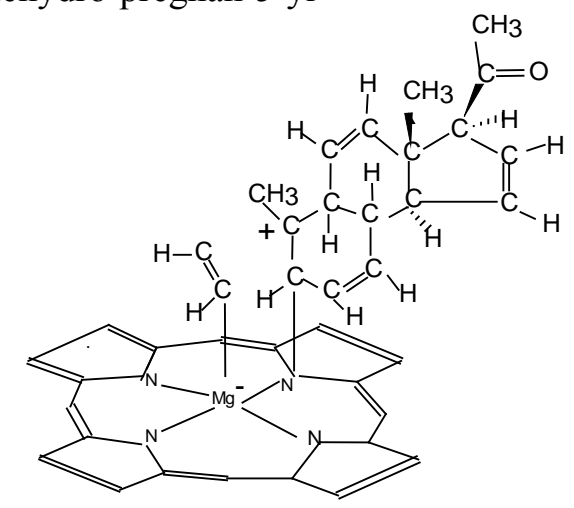


Mg.1, ethynyl.porphin. des-A-6,7,11,12,15,16hexa-dehydro-pregnan-N5-yl. (13) [10]

$$
\Delta \mathrm{H}=-0.08050 \mathrm{~h}
$$

The charge on the ethyne adduct was 0.07 , that on the phenanthrenyl entity 0.00 . These change at the transition state for the adducts to bond.

\subsection{The formation of Mg.1,2-(10-des-A- 6,7,11,12,15,16-hexa-dehydro-pregnan-N5- yl)-ethen-1-yl.porphin.}

The Mg.1,ethynyl.porphin.des-A-6,7,11,12,15,16hexa-dehydro-pregnan-N5-yl may bond as,

Mg.ethynyl.porphin. des-A-6,7,11,12,15,16-hexadehydro-pregnan-N5-yl $\rightarrow$

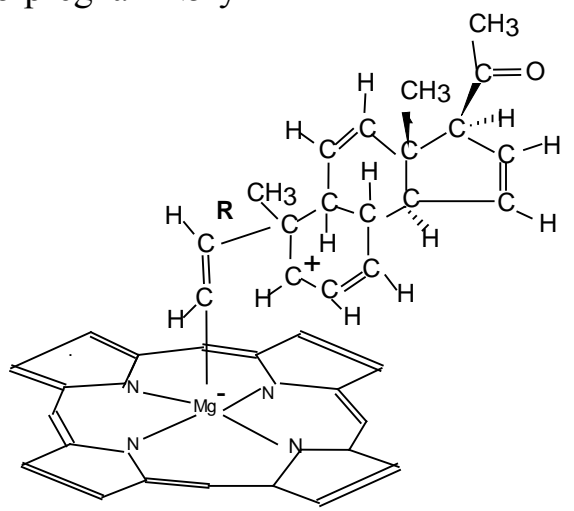

Mg.1,2-(10-des-A-6,7,11,12,15,16-hexa-dehydropregnan-N5-yl)-ethen-1-yl.porphin (14) [11]

$$
\Delta \mathrm{H}=0.04095 \mathrm{~h}
$$

The form of the potential energy surface for the bonding is shown in Fig.3.

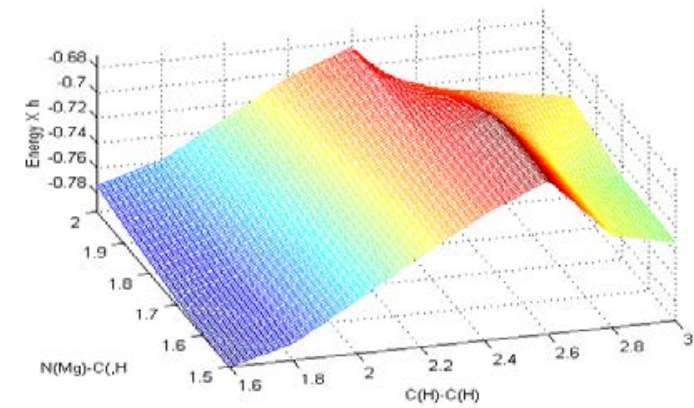

Fig.3. The reactant is near $(3.0,1.5)$, the product at $(1.6,1.5)$. The saddle point is near $(2.5,1.9)$. The energy is $-1988+\mathrm{X}$ h.

The activation energy for bonding was $0.126 \mathrm{~h}$, that for scission, $0.105 \mathrm{~h}$. T he charge on the adduct was -0.11 . However, at the transition state, $\mathrm{R}=2.03 \mathrm{~A}$, the charges redistribute to give the values, ethyne, -0.29 , phenanthrenyl adduct, 0.08 , conducive to the bonding ensuring a steroid $\mathrm{C} 10$ $\beta$-methyl group. This is assisted if the magnetic vector of the exciting radiation is pointing upwards towards the observer and steric factors assist.

\subsection{The formation of Mg.1, porphin.2- (des-A-6,7,11,12,15 ,16-hexa-dehydro- pregnan-10-yl)-ethen-N1-yl.}

Excitation of the Mg.1,2-(10-des-A6,7,11,12,15,16-hexa-dehydro-pregnan-N5-yl)ethen-1-yl.porphin may lead to severance of the C$\mathrm{N}$ bond as,

Mg.1,2-(10-des-A-6,7,11,12,15,16-hexa-dehydropregnan-N5-yl)-ethen-1-yl.porphin $\rightarrow$

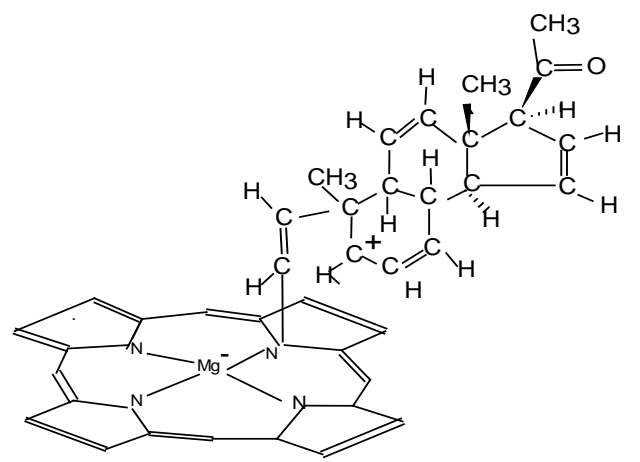

Mg.1, porphin.2-(des-A-6,7,11,12,15,16-hexadehydro-pregnan-10-yl)-ethen-N1-yl. (15) [12]

$$
\Delta \mathrm{H}=0.05905 \mathrm{~h}
$$

The activation energy was the same as the enthalpy change. The charge on the adduct was 0.52 .

\subsection{The formation of Mg.ethynyl.porphin. 2-(des-A-6,7,11,12,15 ,16-hexa-dehydro- pregnan-10-yl)-ethen-N1-yl}

The Mg.1,porphin.2-(des-A-6,7,11,12,15 ,16hexa-dehydro-pregnan-10-yl)-ethen-N1-yl. may add a further ethyne molecule as,

ethyne + Mg.1,porphin.2-(des-A-6,7,11,12,15,16hexa-dehydro-pregnan-10-yl)-ethen-N1-yl. $\rightarrow$ 


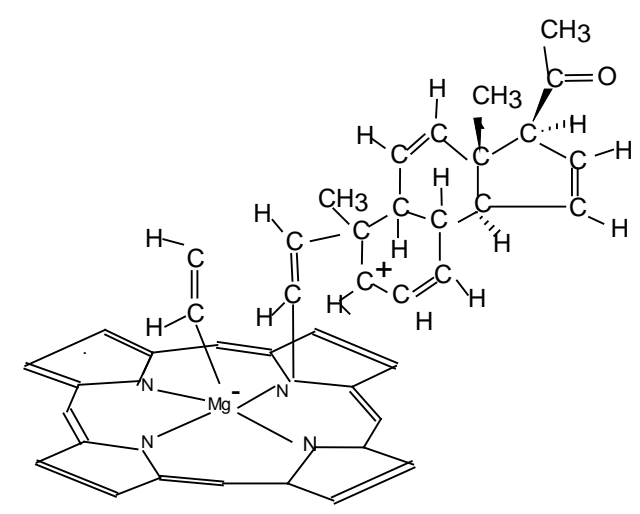

Mg.1,ethynyl.porphin.2-(des-A-6,7,11,12,15,16hexa-dehydro-pregnan-10-yl)-ethen-N1-yl (16)

[13]

$$
\Delta \mathrm{H}=-0.00431 \mathrm{~h}
$$

The charge on the ethyne was 0.07 , that on the phenanthrenyl adduct -0.53 .

\subsection{The formation of Mg.1, 4-(des-A- 6,7,11,12,15, 16-hexa-dehydro-pregnan-10- yl)-but-1,3-dien-1-yl.porphin. \\ The Mg.1,ethynyl.porphin.2-(des-A-6,7,11,12,15 ,16-hexa-dehydro-pregnan-10-yl)-ethen-N1-yl may bond as,}

Mg.1,ethynyl.porphin.2-(des-A-6,7,11,12,15,16hexa-dehydro-pregnan-10-yl)-ethen-N1-yl (16) $\rightarrow$

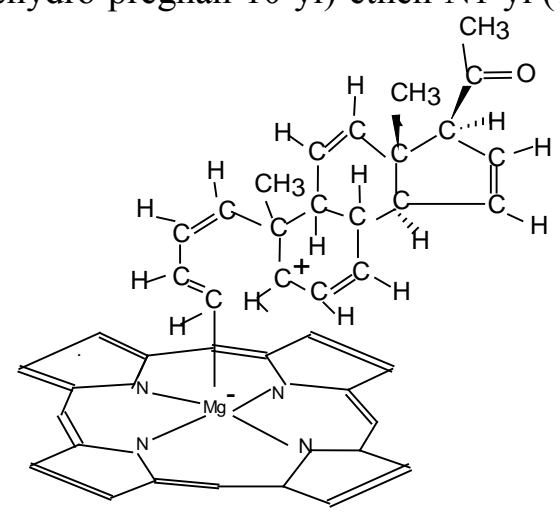

Mg.1,4-(des-A-6,7,11,12,15,16-hexa-dehydropregnan-10-yl)-but-1,3-dien-1-yl.porphin (17)

$$
\Delta \mathrm{H}=-0.16613 \mathrm{~h}
$$

The activation energy for bonding was $0.09 \mathrm{~h}$, and for the reverse reaction $0.24 \mathrm{~h}$. The charge on the adduct was 0.20 .

3.16 The formation of Mg.1, 6,7,11,12,15 ,16-hexa-dehydro-pregnan-4-yl.porphin.

The Mg.1,4-(des-A-6,7,11,12,15,16-hexa-dehydropregnan-10-yl)-but-1,3-dien-1-yl.porphin may bond to form the steroid structure as,
Mg.1,4-(des-A-6,7,11,12,15,16-hexa-dehydropregnan-10-yl)-but-1,3-dien-1-yl.porphin $\rightarrow$

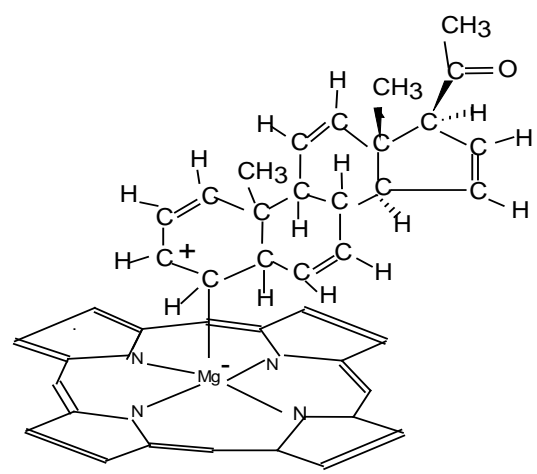

Mg.1,1,2, 6,7,11,12,15,16-octa-dehydro-pregnan4-yl.porphin. (18)

$$
\Delta \mathrm{H}=-0.13230 \mathrm{~h}
$$

The activation energy to close was the ring was 0.052 , that for scission $0.174 \mathrm{~h}$. The charge on the adduct was 0.02 .

\subsection{The formation of Mg.1, 1,2,6,7,11,12,15 ,16-octa-dehydro-3-hydroxy-pregnan-4- y.porphin.}

The Mg.1,1,2, 6,7,11,12,15,16-octa-dehydropregnan-4-yl.porphin may be susceptible to reaction with hydroxyl radicals in the environment [18] as,

$2 \mathrm{H}_{2} \mathrm{O} \rightarrow \mathrm{H}_{2}+2 \mathrm{OH}^{\cdot} \Delta \mathrm{H}=0.18915 \mathrm{~h}$

Mg.1,1,2, 6,7,11,12,15,16-octa-dehydro-pregnan4-yl.porphin $+\mathrm{OH}^{\cdot} \rightarrow$

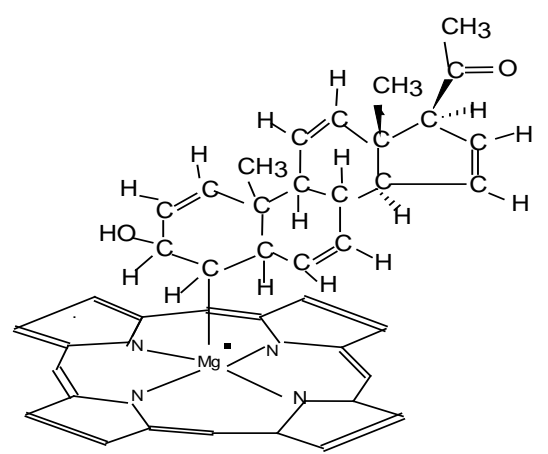

Mg.1,1,2, 6,7,11,12,15,16-octa-dehydro-3hydroxy-pregnan-4-yl.porphin: (19) [16]

$$
\Delta \mathrm{H}=0.02525 \mathrm{~h}
$$

The charge on the adduct was -0.59 . 
3.18 The formation of $1,2,6,7,11,12,15,16-$ octa-dehydro-3-hydro-pregnane

With further reaction with hydroxyl radical abstraction of a hydrogen atom on $\mathrm{C} 5$ the Mg.1,1,2, 6,7,11,12,15,16-octa-dehydro-3hydroxy-pregnan-4-yl.porphin becomes unstable and the catalyst spontaneously separates.

Mg.1,1,2, 6,7,11,12,15,16-octa-dehydro-3hydroxy-pregnan-4-yl.porphin ${ }^{*}+\mathrm{OH}^{-} \rightarrow \mathrm{H}_{2} \mathrm{O}$ + Mg.porphin +

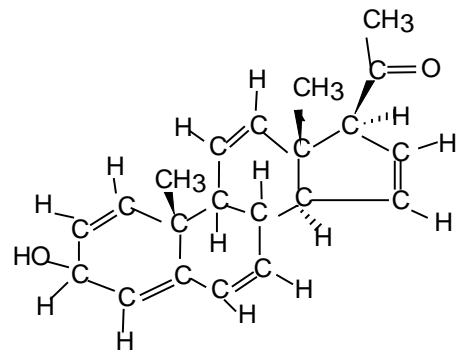

1,2,6,7,11,12,15,16-octa-dehydro-3-hydroxypregnane. (20)

[17]

$$
\Delta \mathrm{H}=-0.22953 \mathrm{~h}
$$

If the molecule is in the excited state then this reaction is more favourable.

\subsection{The formation of $1,2,6,7,11,12,15,16-$ octa-dehydro-pregnane}

The 1,2,6,7,11,12,15,16-octa-dehydro-3-hydroxypregnane. (20) may lose hydrogen by acid-base catalysis as,

\section{1,2,6,7,11,12,15, 16-octa-dehydro-3-hydroxy-} pregnane. (20) $\rightarrow \mathrm{H}_{2}+$

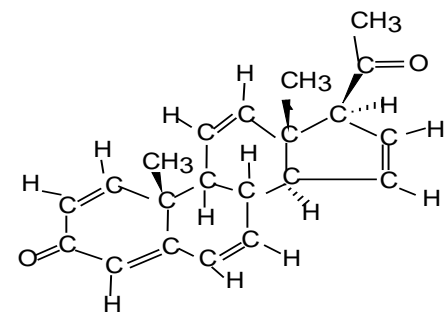

1,2,6,7,11,12,15,16-octa-dehydro-pregnane (21)

$$
\Delta \mathrm{H}=-0.00696 \mathrm{~h}
$$

\subsection{The formation of pregnane}

The 1,2,6,7,11,12,15,16-octa-dehydro-pregnane may be hydrogenated as shown here, or at several other steps in the proposed mechanism. These reactions are usually favourable as, 1,2,6,7,11,12,15,16-octa-dehydro-pregnane (21) + $4 \mathrm{H}_{2} \rightarrow$<smiles>CC(=O)[C@H]1CC[C@H]2[C@@H]3CCC4=CC(=O)CC[C@]45C[C@@]35CC[C@]12C</smiles>

progesterone (22)

$$
\Delta \mathrm{H}=-0.16448 \mathrm{~h}
$$

\section{Conclusion}

The

photochemically

catalyzed copolymerization of the simple gases, ethyne and propyne provides a plausible explanation for the three trans bridges: $\mathrm{C}: \mathrm{D} / \mathrm{B}: \mathrm{C} / \mathrm{A}: \mathrm{B}$, the steroid $\mathrm{C} 10$, $\mathrm{C} 13$ and $\mathrm{C} 17 \beta$-substituents, the 3-oxo substituent, and the 4,5 double bond, where steric effects and charges in the presence of the exciting magnetic field are determinant. The electrophilicity of C11 versus $\mathrm{C} 12$ also becomes evident in the final structure.

Further work at a higher accuracy may alter the values given here.

\section{Acknowledgements:}

Appreciation is expressed for the advice and support given to this project by Professor Curt Wentrup of the University of Queensland.

Appreciation is also expressed to APAC for facilities at the ANU and QMAS facilities at UQ, and the assistance of Mr.D.Green, H.Hartig, M.Hankel and M.Nicholls

\section{References:}

[1] G.P.Moss, Nomenclature of steroids, Pure \& Appl. Chem., 81,(10), 1989, pp.1783-1822.

[2] W.R.Butt, Hormone Chemistry, D.van Nostrand Comp. Ltd., London, 1967.

[3] B.W. O'Malley and A.R. Means, Female steroid hormones and target cell nuclei, Science, 183, 1974, pp.610-620.

[4] A.L.Lehninger, Biochemistry,Worth, New York, 1975, pp. 298,296,687,683,680. 
[5] S.Dev, Handbook of Terpenoids: Volume I: Triterpenoids,CRC Press, 2017, pp.581.

[6] N.Aylward, and N.R.Bofinger, Possible origin for porphin derivatives in prebiotic chemistry - a computational study, Orig.Life Evol. Biosph. vol.35(4), 2005, pp.345-368.

[7] S.L.Miller and L.E.Orgel, The Origins of Life on Earth, Prentice-Hall Inc.,Englewood Cliffs, N.J.,1975.

[8] L.E.Snyder and D.Buhl, Interstellar methylacetylene and isocyanic acid, Nature, 243, 1973, pp.45-46.

[9] K.Seki, M.He, R.Liu and H.Okabe, Photochemistry of cyanoacetylene at 193.3 nm. J.Phys.Chem.,100,1996,pp.5349-5353.

[10] N.N.Aylward, a nd N.R.Bofinger, Carbon monoxide clusters in the formation of Dsugars and L-amino-acids in prebiotic molecular evolution on Earth, in G.Palyi, C.Zucchi, L.Cagliotti, (eds.), Progress in Biological Chirality, Elsevier,Oxford (GB), 2004, ch2, pp.429,

[11] N.N. Aylward, The synthesis of terpenes in prebiotic molecular evolution on Earth, in WSEAS New Aspects of Biomedical Electronics and Biomedical Informatics. Eds.
C.A.Long,
P.Anninos,
T.Pham,

G.Anastassopoulos， N.E.Mastorakis，2008, pp.202-207

[12] Gaussian03, Users Reference, Gaussian Inc.,Carnegie Office Park, Bldg.6., Pittsburgh, PA 15106, USA,2003.

[13] W.J.Hehre, L.Random, P.V.R. Schleyer, and J.A.Pople, Ab Initio Molecular Orbital Theory, Wiley, New York, 1986.

[14] J.A.Pople, H.B.Schlegel, R.Krishnan, D.J. DeFrees, J.S. Binkley, M.J. Frisch, R.A.Whiteside, R.J.Hout and W.J.Hehre, Molecular orbital studies of vibrational frequencies, Int.J.Quantum Chem. Symp. vol.S15, 1981, pp.269-278.

[15] N.N.Aylward, The prebiotic synthesis of progesterone (C and D rings). WSEAS.2019.

[16] J.P.Collman, L.S.Hegedus, J.R.Norton, R.G. Finke, Principles and Applications of Organotransition Metal Chemistry, University Science Books, Mill Valey, California,,1987.

[17] D.Mansuy, J.P.Battioni, D.Dupree, E.Santoni, J.Am.Chem.Soc.104, 1982, pp.6159-6161.

[18] F.K.Fong, Light Reaction Path of Photosynthesis, Springer Verlag, 1982, pp.344. 